\title{
Research on the Model and Dynamic Mechanism of Chinese Sports Town Based on European and American Experience
}

\author{
Ze Zhang ${ }^{1}$ \\ ${ }^{1}$ Department of physical education of zhejiang international studies university, hangzhou zhejiang China 310023 \\ *Corresponding author. Email: 110173249@qq.com
}

\begin{abstract}
Based on the methods of summarization, deductive logic and literature research, the study firstly analyzes the construction model of typical small towns with sports characteristics in Europe and America. Secondly, based on the experience of Europe and the United States and the actual situation of Chinese sports characteristics towns, the study puts forward the models conception of Chinese sports towns. Finally, it is concluded that the dynamic mechanisms for the construction of sports characteristics towns in China.
\end{abstract}

Keywords: Europe and America, Chinese sports characteristic town, model, dynamic mechanism, sports industry.

\section{INTRODUCTION}

Characteristic towns are an important way to promote supply-side structural reform and new urbanisation in China. In the context of the rise of national fitness as a national strategy and the promotion of the construction of a healthy China, the sports industry has set off a new climax of development, and the construction of sports characteristic towns as a new development mode of the sports industry has continued to emerge. At present, both the domestic industry and academia are competing for attention to this, and different types and themes of sports characteristic towns are proposed based on different perspectives and criteria[1-2]. As an important part of the characteristic town in China, the sports characteristic town model and how to build are particularly important to influence its survival and development. In the context of the world entering globalisation, towns and cities export their influence to every corner of the world through the advantages of specialisation, and sports towns in Europe and America have been at the forefront of the world, and the summary and analysis of the experience of sports towns in Europe and America is also an issue worthy of attention. Based on this, it is the starting point of this study to analyse and summarise the experience of sports town construction in Europe and America, and to explore the problems of the model and dynamic mechanism of sports town in China.

\section{CONSTRUCTION EXPERIENCE AND INSPIRATION OF SPORTS TOWNS IN EUROPE AND AMERICA}

\subsection{Sports event towns in the USA}

Eugene, home to the University of Oregon and the famous Hayward Field, is the birthplace of some of the most famous and respected track and field in the world. The University of Oregon has a long tradition of track and field, with several Olympians, American recordsetters, NCAA champions and other outstanding athletes under the leadership of the famous track and field coach - Bill Bowerman. Bowerman also co-founded Blue Ribbon Sports, the predecessor of Nike, with Phil Knight, and promoted the local track and field-related industries. Eugene is home to not only a traditional event, the Prefontaine Classic, but also a US Olympic qualifying event and a split of the IAAF Diamond League. In addition, the local running culture and private events have flourished, and the Eugene City Marathon has become a major local event, with trails or cross-country hills, river front, campus, city and mountains, making Eugene the "City of Track and Field"[3]. Bloomington, Indiana's signature event since 1951 is "the Little Five Hundred", where a diverse crowd gathers in Bloomington in mid to late April for the"World's Greatest College Weekend". As the home of equestrian sports in the United 
States, Lexington, Kentucky, has developed and built a major horse-related industry of breeding, quarantine, trading and competition, with horse farms, showrooms and tracks. Moreover, the Rolex Kentucky Three-Day Event, the top international equestrian competition, is also located in Bloomington[4]

In terms of size, these three areas are basically small towns or small cities, and are well-known sporting event towns in the United States, all of which have some type of sporting event industry rooted and anchored in the area, driving local development through sporting events. Due to the correlation effect that exists in the sporting event industry, the town gradually formed with the sporting event industry as the core, driving the emergence and development of construction, equipment and equipment manufacturing, urban environment and infrastructure, other service industries, media industry, gaming industry and tourism in the town.

\subsection{French sports and leisure towns}

The French town of Chamonix, situated at the foot of the main Alpine peak of Mont Blanc, is blessed with natural advantages that make it ideal for outdoor sports. In August 1786, the hunters of Chamonix climbed Mont Blanc, the highest mountain in Europe, and this led to the start of Alpine mountaineering and the development of outdoor sports in the region. As a result of the first Winter Olympics in Chamonix in 1924, ice rinks were added for skating and hockey competitions, and the area became a worldwide training centre for ski instructors. There are also more than 5,000 rock climbing routes, ice climbing and mountaineering routes, and skiing, paragliding and rappelling are widely practised in the region. In addition to this, there are a large number and different levels of hotels, house rentals, holiday centres and other property hospitality services. Sharmouni, despite having only 13,000 permanent residents, receives more than 2 million mountain skiers and daily visitors every year, making it a destination for many outdoor sports enthusiasts[5].Holiday industry will be driven by the alpine outdoor sports and leisure projects, forming a development model of a town with a combination of "sports and leisure projects + tourism and holiday". At the same time, the town will be a destination for sports and leisure events, and a professional sports and leisure support system and education and training system will be established to promote the formation of a sports and leisure town.

\subsection{Italian Sporting Goods Manufacturing Characteristic Towns}

Montebelluna, a town in the northern Italian province of Treviso with a long history of shoemaking, has been a world-renowned producer of snow and ice-sports related footwear since the $1970 \mathrm{~s}$, with around $80 \%$ of the world's racing boots, $75 \%$ of ski boots, $65 \%$ of ice skates, $55 \%$ of mountaineering shoes and $25 \%$ of The production of inline skates, for example, amounts to 35 million pairs per year and annual sales of more than $€ 1.5$ billion. This site contains production[6]. chains for plastics, moulding, machinery, prototyping, accessory production, product design, research and development, style analysis, marketing and distribution, with companies in each chain forming a sports shoe manufacturing cluster according to a division of labour[7]. The industrial clusters established in the town of Montebelluna promote the concentration of a large number of enterprises to form an industrial agglomeration, which leads to the improvement of supporting facilities such as commercial, residential and public service facilities, thus contributing to the development of the local economy and the improvement of the city's service functions. The town of Italy, relies on traditional craftsmanship Montebelluna, and technology to develop a sporting goods manufacturing industry, forming the characteristics of a "sporting goods manufacturing industry cluster+ urban support services" .

\subsection{Insights from the construction of sports towns in Europe and America}

From the construction and development of sports towns in Europe and the United States, it can be found that the actual characteristics of the town are based on the town's own fundamental, according to the natural endowment or special craft tradition to choose the sports industry as the leading development industry of the town, and through the development of the sports industry to drive the development and progress of the related industries, so as to drive the town's industrial and economic development and prosperity. In terms of the construction and development of sports towns, the experience of Europea and America can provide some references for China. First of all, the geographical space and natural conditions of the sports town are the basic conditions for industrial development. The survival and development of a sports town is based on industry, and the town's own characteristics and conditions are the basic elements of industrial development. Secondly, the sports town is highlighted by sports, and the special features of the town also lie in the sports industry and its related industries. Sports goods manufacturing, sports and leisure, sports events and other industries that are key to the construction and development of a sports town. Combining such sports industries with the town and forming a sports industry atmosphere that are an important goal in building a sports town.

\section{CONCEPTION OF A SPORTS TOWN MODEL IN CHINA}




\subsection{Industrial cluster model of sporting goods manufacturing characteristic town}

As the world's top sporting goods manufacturing country, the sporting goods manufacturing industry is an important part of China's sports industry, with the total output and added value of sporting goods and related products manufacturing in China amounting to 119.61 billion yuan and 286.39 billion yuan respectively in 2016 , accounting for $62.9 \%$ and $44.2 \%$ of the total output and added value of the national sports industry respectively[8]. Chen Dai Town in Jinjiang, Fujian Province, is an early town in China engaged in the sports goods manufacturing industry, which is a product of reform and opening up and undertaking international industrial transfer. The sports footwear manufacturing industry cluster is a production network and production support network formed by enterprises and production support institutions to complete the footwear, promoting the growth of enterprises within the cluster and reflecting the competitiveness[9]. China's sporting goods manufacturing town is characterised by sports equipment, sportswear and footwear as the main products, and the town's enterprises are also mostly of the production and processing type, with fewer design $\mathrm{R} \& \mathrm{D}$ and marketing enterprises, a shorter value chain, fewer economic benefits gained, and fierce competition with each other. With the improvement of technology and the emphasis on brand awareness, enterprises gradually began to increase technological innovation and create independent brands, gradually extending from the production and processing stage of the sporting goods manufacturing industry to the $R \& D$ and marketing stage of the value chain, thus forming a sporting goods manufacturing industry cluster.

The sporting goods manufacturing industry cluster is a network of mutual cooperation between enterprises and production support institutions in the value chain of the sporting goods manufacturing industry to form a production network and a production support network to jointly complete the production of sporting goods[1011].For a sporting goods manufacturing town, improving the network of mutual cooperation between enterprises and institutions at different stages of the value chain of the sporting goods manufacturing industry is an important task. China's sporting goods manufacturing industry grew and expanded along with the economic reform and opening up and the international industrial transfer. This also limits the development of clusters. Therefore, in the process of building a sporting goods manufacturing town with an ndustrial cluster model, the establishment of a complete sporting goods manufacturing industry value chain is an important task, which will lead to the completion of the town's industrial system and the formation of a close cooperation network between enterprises and various production support institutions to form an industrial cluster and promote the growth and development of the town.

\subsection{Sports and leisure town with industrial integration model}

According to international experience, when the GDP per capita exceeds US $\$ 5,000$, the tourism and sports tourism industry will see a "blowout". China's GDP per capita exceeded US\$8,000 in 2016, and the number of domestic tourists reached 5.01 billion in 2017, an increase of $12.8 \%$ over the same period the previous year[12]. Faced with the development and growth of tourism in China and the deepening of the national lifestyle of pursuing entertainment and leisure, the combination of sports and tourism has gradually become a new development trend. Moreover, with the rise and indepth development of the concept of national fitness and healthy China, the importance of improving health through sports means has become more and more prominent, and the combination of sports and health has become increasingly close. China's sports and leisure characteristic town is regarded sports entertainment and holiday tourism, sports and health combined as the concept, sports and leisure projects and training, tourism, health and other industries in the town are achieved integration. Sports and leisure programs, related training, and tourism and health programs are the characteristic contents of the town, and the town will be built into a scenic destination for tourism and holiday, eventually forming a sports and leisure characteristic town construction model that combines sports industry, tourism and health and other industries with a town.

\subsection{Sports event town with a combination of event industry chain and industry integration mode}

Although the definition of sports events is not quite the same based on different perspectives, from the concept and characteristics of sports events, not only sports events use the products of related industries as their own production factors to generate products, but also sports events drive the development of downstream industries, with obvious industry-related attributes. Therefore, in the process of building a sports event town, it is necessary to build one or more sports events as the leading industry to drive the development of sports event related or auxiliary industries. Moreover, it is also necessary to consider building industries related to the event or other sports training and to form a complete sports event industry chain in the town, so as to drive the development of the town's industry.

While creating a characteristic sports event industry chain in the town, it is also possible to expand and integrate sports events and their related industries into the tourism industry, forming a characteristic town that combines sports event viewing, training and tourism experience with the sports event industry as the leading industry and the tourism industry as the supporting 
industry. The main reason for the survival and development of sporting event characteristic towns is that sporting events are held in the town and become branded events, and the key to solving this problem lies in the type of sporting events in the town. Therefore, the type of sporting events should fully consider the characteristics of the natural and socio-cultural environment, such as the spatial and geographical conditions of the town, and achieving an effective fit between sporting events and the town is a key consideration.

\section{THE DYNAMIC MECHANISM OF THE CONSTRUCTION OF SPORTS TOWN IN CHINA}

\subsection{Realistic background of the changing social environment development of the sports character town}

Sports towns are also known as "sports and leisure towns" in China. As a product of the national policy to promote the development of sports towns and sports industry, the sports town is an important carrier for China to promote the strategy of "national fitness" and to promote the normalisation and popularisation of national sports and the development of sports industry.The development of mountain outdoor, ice and snow sports, water sports and other emerging sports in China in recent years has also led to the emergence of fitness and leisure industries, the increasing integration of sports and tourism, the construction of small towns in full swing throughout China, the concept of injecting sports elements into small towns has gradually become a popular trend, and sports characteristic towns have also emerged along with the trend of realistic social environment changes, injecting sport into towns are also emerging as a new driving force in the development of the sports industry. The changes in the social environment have led to corresponding changes in the perceptions and values of our nationals and their lifestyles, providing a rare opportunity for the emergence and development of sports towns in China in recent years.

\subsection{System supply for the construction of sports towns}

The changes in China's social environment provide opportunities for the sprouting and construction of sports characteristic towns, which also prompt the relevant national policies and systems to adjust and change, providing institutional safeguards development of sports characteristic towns in China. The policies and systems promulgated by the state, provinces and municipalities in relation to sports towns show that, as a product of the supply-side reform of the national sports industry and a platform to promote the development of China's sports industry, sports towns will play an important role in promoting the development of China's sports industry, and the corresponding national and local policies and systems provide a good policy environment and opportunities for the development of sports towns in China. The various national and local policies and systems provide a good policy environment and opportunities for the development of sports towns in China, and point the way for the development of sports towns.

\subsection{Innovative ideas to build a town sports culture with special content}

The construction of sports characteristic town should establish the concept of cultural construction as the goal, and innovate the characteristic content of sports characteristic town. Sporting goods manufacturing characteristic town is mainly developed with the production and manufacture of sporting goods and its upstream and downstream industries as the core, the production of sporting goods is the content of the town building, forming the industrial culture atmosphere of the sporting goods manufacturing characteristic town. Sports events are the core content of a sports event town. The types of sports events and the construction of a special sports event culture in the town, as well as how to drive the development of related industries through sports events are what needs to be considered in the construction of a sports event town. The core content of a sports and leisure town is the sports and leisure projects, which will be organically combined with the town to form a sports and leisure cultural atmosphere and create a sports and leisure characteristic product content of the town. In addition, the location of the sports character town should also be innovative in concept, according to the characteristics of the area in which the town is located, to establish the sports character content in line with the town's own characteristics, to avoid homogenisation. The relationship between sports characteristics and the town is one of content and form, with the town being the external form and the sports characteristics being the essence that determines the construction and development of the town.

\subsection{Diversification mechanism of the investment and construction main body of the sports characteristic town}

As a product of the national promotion of urbanisation and supply-side reform in the context of the new normal, the construction of sports characteristic towns should combine government and social forces to form an innovative mechanism of diversified investment and construction subjects. The government is the responsible body for cultivating sports characteristic towns, the policy maker and guarantor of sports characteristic town construction, the integrator of sports characteristic town funding implementation and other 
tasks, and the supervisor of sports characteristic town construction. Social forces are the executors of the policies of sports characteristic towns and the practitioners of building sports characteristic towns. The government focuses on macro-level planning and construction, while social forces focus on micro-level implementation and practice. The model of combining government and social forces can bring the strengths into promoting the construction of sports characteristic towns.

\section{CONCLUSION}

The experience of the construction and development of sports towns in Europe and the United States provides some reference for China, the changes in the national social environment and the opportunities of the corresponding policies provide guarantees for the construction and development of sports towns, the construction of the cultural content of sports characteristics indicates the development goals and directions for sports towns, and the diversified investment and construction bodies provide support for the smooth development of sports towns. The diversified investment and construction bodies provide support for the smooth development of sports town construction, and also lay the foundation and guarantee for promoting the further development and growth of the Chinese model of sports town.

\section{REFERENCES}

[1] State General Administration of Sports. Notice of the General Office of the General Administration of Sports on promoting the construction of sports and leisure characteristic towns[EB/OL]. http://www.sport.gov.cn/n316/n336/c802334/conte nt.html.

[2] Lei Zhang(2018). Sports and leisure characteristic town:concept, types and development path[J]. Sports Science,38(1):18-26.

[3] Tencent Sports. A visit to Eugene: What makes her America's "City of Track and Field" [EB/OL]. http://sports.qq.com/a/20151019/027628.htm.

[4] Peng Peng News. Hundreds of sports towns have been built, so let's see what the Americans are doing to avoid the"bad ones"[EB/OL]. http://news.163.com/17/0526/09/CLBQCARM000 187VE.html.

[5] Sohu Finance. Ice and snow sports town: Who will become China's Shamuni [EB/OL]. http://www.sohu.com/a/146565622_483560.

[6] New Travel World. Eight conditions for success of sports towns from three foreign cases [EB/OL]. https://xueqiu.com/8032522061/86742669.
[7] Chunni Fang(2009). The success mechanism and inspiration of foreign sports footwear clusters: the example of the sports footwear production base in Montebelluna, Italy[J].Journal of Wuhan Institute of Sports, $43(2): 48-51$.

[8] National Bureau of Statistics National General Administration of Sports. 2016 National sports industry total scale and value added data announcement[EB/OL]. http://www.stats.gov.cn/tjsj/zxfb/201801/t20180113 _1573014.html.

[9] Ze Zhang(2018). Research on the network of sporting goods manufacturing industry cluster and the growth mechanism of enterprises--based on the data of Jinjiang, Fujian[J].Journal of Shenyang Institute of Sports,37(1):57-58.

[10] Ze Zhang, Huping Cong(2013). Study on the economic network mechanism of sports shoes manufacturing industry cluster in Jinjiang City, Fujian Province[J]. Sports Science,33(1):23.

[11] Ze Zhang(2018). Network structure and characteristics analysis of sporting goods manufacturing industry clusters $[\mathrm{J}]$. Zhejiang sports science,40(3):25-28.

[12] National Tourism Administration Data Center. China Tourism Research Institute: China's outbound tourism increased by $7 \%$ year-on-year in 2017[EB/OL]. http://www.199it.com/archives/688186.html. 